\title{
Estimation of L-lysine Requirement by Indicator Amino Acid Oxidation Method Using Random Effects Model
}

\author{
Kohsuke Hayamizu*, Keisuke Matsumoto, Nobuo Izumo, Makoto Nakano \\ Department of Pharmacy, Yokohama University of Pharmacy, Yokohama, Japan \\ Email address: \\ k.hayamizu@hamayaku.ac.jp (K. Hayamizu) \\ ${ }^{*}$ Corresponding author \\ To cite this article: \\ Kohsuke Hayamizu, Keisuke Matsumoto, Nobuo Izumo, Makoto Nakano. Estimation of L-lysine Requirement by Indicator Amino Acid \\ Oxidation Method Using Random Effects Model. International Journal of Nutrition and Food Sciences. Vol. 9, No. 2, 2020 , pp. 63-68. \\ doi: $10.11648 /$ j.ijnfs. 20200902.14
}

Received: April 7, 2020; Accepted: April 22, 2020; Published: May 14, 2020

\begin{abstract}
In recent years, it has been suggested that the method for determining the requirements for indispensable (essential) amino acids be changed from the nitrogen balance method to the tracer methods. In particular, the indicator amino acid oxidation (IAAO) method has been implemented. Although the requirements for indispensable amino acids have been reported in several independent trials, no reported study has statistically integrated these data. In addition, the requirement as obtained from the IAAO method reported to date is the estimated average requirement (EAR), which will be met nutrient requirements in 50\% of population only; thus, the risk of deficiency cannot be ruled out from a nutritional perspective. In this study, we statistically synthesized the data of multiple required amounts of lysine obtained by the IAAO method and attempted to accurately estimate the EAR. Further, we estimated the recommended dietary allowance (RDA) value from the obtained estimated EAR value. Analysis using a random effects model estimated that the EAR of lysine in healthy adults was approximately $37 \mathrm{mg} / \mathrm{kg}(95 \% \mathrm{CI}$ : $31.2-42.5)$. In addition, the RDA was estimated to be about $46 \mathrm{mg} / \mathrm{kg}$. These values are higher than the previously reported value of $30 \mathrm{mg} / \mathrm{kg}$.
\end{abstract}

Keywords: L-lysine, Indicator Amino Acid Oxidation, Estimated Average Requirement, Recommended Dietary Allowance

\section{Introduction}

Proteins are made up of 20 different L-amino acids linked by peptide bonds. They are important components of organisms, and their types differ depending on the number and types of amino acids, and the sequence of the peptide bonds. In humans, proteins cannot be biosynthesized from other nutrients in the body and must be consumed. Thus, proteins are essential nutrients. When there is a protein deficiency, kwashiorkor can arise [1]. Of the 20 amino acids, humans can synthesize 11 from other amino acids or intermediate metabolites. The remaining 9 amino acids must be consumed from the diet, and are referred to as indispensable (essential) amino acids. The indispensable amino acids are lysine, histidine, isoleucine, leucine, methionine, phenylalanine, threonine, tryptophan, and valine. Despite years of research, the requirements for amino acids, especially indispensable ones, in humans remain a topic of discussion. Study of these requirements has been conducted with priority being placed on L-lysine, the first limiting amino acid in wheat. Conventionally, the nitrogen balance method has been used as an experimental method for estimating amino acid requirements [2]. However, in recent years, research using tracers has attracted attention as an alternative [2, 3]. This method was used for estimating the amino acid requirements of healthy adults in the "Joint FAO/WHO/UNU expert consultation on protein and amino acid requirements in human nutrition" in 2002 [4-13]. At the above-mentioned scientific conference, several requirements for L-lysine for healthy adults were presented, as determined using different methods included the nitrogen balance method. This requirement was determined to be $30 \mathrm{mg} / \mathrm{kg}$ based on the result of the best approach at that time, $24 \mathrm{~h}$ indicator amino acid balance (IAAB) studies [4, 11, 12]. Alternatively, a commonly used tracer test for estimating the requirements for indispensable amino acids is also available, namely, the indicator amino acid oxidation (IAAO) method. However, no re-evaluation of the results regarding L-lysine requirement obtained by the IAAO method has been performed using a statistical approach (Issue 1). 
In the IAAO approach, measurements of amino acids other than the tested amino acid are used to determine the requirement for the tested amino acid. For example, to determine the lysine requirement using the IAAO technique, oxidation of an (indicator) amino acid (e.g., L- $\left[1-{ }^{13} \mathrm{C}\right]$ phenylalanine) has been evaluated $[2,5-10,13,14]$. The theory behind this method is that, if one indispensable amino acid in the diet is below its required level (i.e., is limiting), then none of the other indispensable amino acids can be fully utilized for protein synthesis; as such, the excess amounts are oxidized. As the amount of the indispensable amino acid increases, the others will be progressively better utilized and their oxidation rates will progressively fall to a lower limit at the point where the requirement for the tested amino acid is reached. The oxidation rate of the indicator amino acid (usually L- $\left[1-{ }^{13} \mathrm{C}\right]$ phenylalanine) is measured as $\mathrm{F}^{13} \mathrm{CO}_{2}$ in expired gas. Intake above this amount should no longer influence the oxidation of the tested amino acid, the level of which should remain low and constant. One can thus determine the requirements for the tested amino acid by estimating a threshold value of the indicator amino acid against the intake of the tested amino acid (Figure 1). Therefore, in the IAAO method, it is particularly important to estimate the break point which is interpreted as amount of enough amino acid. The break point is estimated using the two-phase linear regression model by the Seber method, and the $95 \%$ confidence interval $(95 \% \mathrm{CI})$ of the break point is calculated by Fieller's theorem $[15,16]$. The point to note here is the interpretation of the break point and its upper limit of the $95 \%$ CI. These values obtained by the Seber method and Fieller's theorem are the average of the required amount in the former, and the upper limit of the $95 \%$ CI of the average required amount in the latter. In other words, nutritionally, these only determine the estimated average requirement (EAR). In addition, the estimated requirement for L-lysine presented at the 2002 Joint FAO/WHO/UNU expert consultation conference was the result of the break point estimation of IAAB using a two-phase linear regression model, and the value was also interpreted as corresponding to the EAR. The EAR is the amount of a nutrient that is estimated to meet the requirement for a specific criterion of adequacy of half of the healthy individuals of a specific age, sex, and life stage. The EAR is not useful as an estimate of nutrient adequacy in individuals because it is the mean requirement for a group, and the variation around this number is considerable. At the EAR, $50 \%$ of the individuals in a group are below their requirement and $50 \%$ are above it. Therefore, from a nutritional perspective, it is more import that the recommended dietary allowance (RDA) value satisfy about $98 \%$ of a population. The RDA can be determined using information on the inter-individual error of the required amount. However, the WHO report shows only the break point value, that is, the EAR value (Issue 2).

Given Issues 1 and 2 as described above, the purposes of this research are as follows:

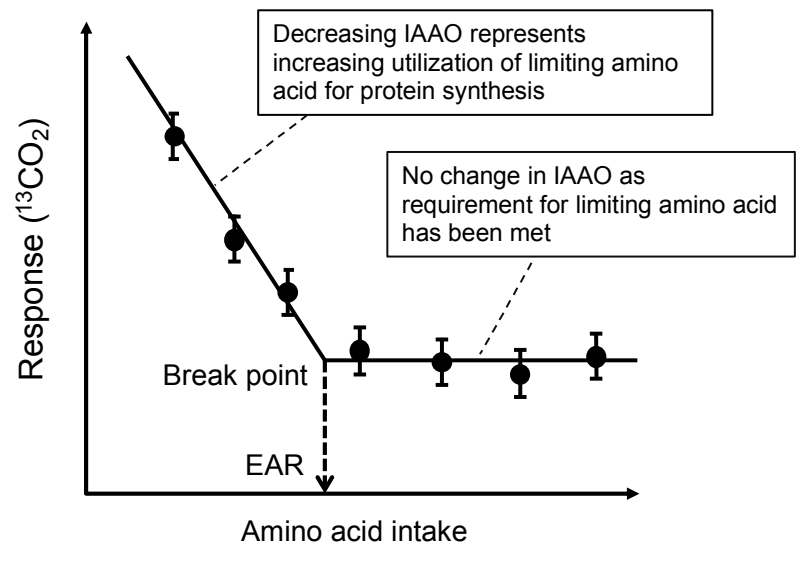

Figure 1. The oxidation pattern of amino acids in studies using the indicator amino acid oxidation (IAAO) method. The lines represent kinetic responses to graded intakes of the tested amino acid. The break point in the oxidation response has been proposed to reflect the physiological requirement for the tested amino acid by an average individual in the population.

1) To estimate the requirement for L-lysine in healthy individuals by performing statistical integrated analysis from multiple estimated required values using the current IAAO breakpoint results.

2) To estimate the RDA from the estimated required amount of L-lysine.

\section{Methods}

\subsection{Indicator Amino Acid Oxidation Studies}

The information on the break point and its 95\% confidence interval obtained from the IAAO method for L-lysine in healthy adult subjects was extracted from the following studies. A summary of each study is provided below and in Table 1.

\subsubsection{Zello et al. (1993) [5]}

This was a human study investigating the lysine requirements of young adult males as determined by the IAAO method, in which the oxidation of $\mathrm{L}-\left[1-{ }^{13} \mathrm{C}\right]$ phenylalanine was measured as the indicator amino acid. It was determined in seven subjects by examining the effects of varying dietary lysine intake on phenylalanine flux and oxidation under dietary conditions of adequate energy and phenylalanine and excess tyrosine. The subjects consumed seven different levels of lysine $(5,10,20,30,40,50$, and 60 $\mathrm{mg} / \mathrm{kg} / \mathrm{d}$ ). The estimated break point was $36.9 \mathrm{mg} / \mathrm{kg} / \mathrm{d}$ with the upper $95 \%$ CI of $58.2 \mathrm{mg} / \mathrm{kg} / \mathrm{d}$ by Fieller's method.

\subsubsection{Duncan et al. (1996) [6]}

This study investigated the lysine requirements of five healthy adult males as determined by the IAAO method, in which the oxidation of $\mathrm{L}-\left[1-{ }^{13} \mathrm{C}\right]$ phenylalanine was measured as the indicator amino acid. The subjects consumed six different levels of lysine $(10,20,30,40,50$, and 60 $\mathrm{mg} / \mathrm{kg} / \mathrm{d}$ ). The estimated break point was $45.0 \mathrm{mg} / \mathrm{kg} / \mathrm{d}$ and the upper $95 \%$ CI was $67.0 \mathrm{mg} / \mathrm{kg} / \mathrm{d}$. 
Table 1. Characteristics of IAAO studies of L-lysine for healthy adult.

\begin{tabular}{|c|c|c|c|c|c|c|c|c|c|}
\hline Study & Location & Subject & $\mathbf{n}$ & Age yr & Height $\mathrm{cm}$ & Weight kg & $\begin{array}{l}\mathrm{BMI} \\
\mathrm{kg} / \mathrm{m}^{2}\end{array}$ & $\begin{array}{l}\text { Energy Intake } \\
\text { kcal/d }\end{array}$ & $\begin{array}{l}\text { Break point [upper } \\
95 \% \mathrm{CI}] \mathrm{mg} / \mathrm{kg}\end{array}$ \\
\hline Zello 1993 & Canada & Healthy adult male & 7 & $24.1(2.0)$ & $176.7(6.0)$ & $72.9(10.9)$ & $23.3(2.4)$ & $3143(260)$ & $36.9[58.2]$ \\
\hline Duncan 1996 & Canada & Healthy adult male & 5 & $27.0(5.7)$ & $177.8(9.0)$ & $79.6(4.3)$ & $25.3(2.2)$ & $3216(120)$ & $45.0[67.0]$ \\
\hline Kriengsinyos 2002 & Canada & Healthy adult male & 5 & $36.4(8.3)$ & $176.2(15.2)$ & $78.5(18.9)$ & $24.9(1.9)$ & $3006(600)$ & $36.6[53.3]$ \\
\hline Kriengsinyos 2004 & Canada & Healthy adult female & 5 & $33.6(5.9)$ & $162.6(5.7)$ & $61.1(12.6)$ & $22.9(3.4)$ & $2452(340)$ & $\begin{array}{l}35.0[43.6] \mathrm{a} \\
37.7[47.9] \mathrm{b}\end{array}$ \\
\hline
\end{tabular}

a: follicular phase, b: luteal phase mean (SD)

\subsubsection{Kriengsinyos et al. (2002) [7]}

To investigate whether splanchnic uptake of the indicator amino acid ([1-13C] phenylalanine) during the fed state alters the estimated lysine requirement, five healthy males were studied at graded levels of lysine intake, with either an oral or an intravenous tracer protocol. This study used only the results from the case of oral ingestion. The subjects consumed six different levels of lysine $(10,20,30,40,50$, and $60 \mathrm{mg} / \mathrm{kg} / \mathrm{d}$ ). The estimated break point was 36.6 $\mathrm{mg} / \mathrm{kg} / \mathrm{d}$ and the upper $95 \%$ CI was $53.3 \mathrm{mg} / \mathrm{kg} / \mathrm{d}$.

\subsubsection{Kriengsinyos et al. (2004) [8]}

The aim of the study was to investigate whether the phases of the menstrual cycle affect lysine requirements in healthy adult females. Five healthy females with regular menstrual cycles were studied in both follicular and luteal phases. The subjects were administered seven different levels of lysine $(10,25,30,35,40,45$, and $60 \mathrm{mg} / \mathrm{kg} / \mathrm{d})$. The estimated break points were $35.0 \mathrm{mg} / \mathrm{kg} / \mathrm{d}$ (upper $95 \%$ CI: $43.6 \mathrm{mg} / \mathrm{kg} / \mathrm{d}$ ) in the follicular phase and $37.7 \mathrm{mg} / \mathrm{kg} / \mathrm{d}$ (upper $95 \%$ CI: 47.9 $\mathrm{mg} / \mathrm{kg} / \mathrm{d}$ ) in the luteal phase.

\subsection{Data Synthesis and Statistics}

To estimate the requirement for L-lysine in healthy individuals, we perform statistical integrated analysis from multiple estimated required values using the current reported IAAO break point results. The integrated analysis was stratified by sex. The standard error (SE) of break point was directly calculated from reported uncertainty measures $(95 \%$ CI). The data synthesis of break points across trials was performed using the DerSimonian and Laird method [17]. Details of the integration method are as follows:

$B P_{i}$ : estimated break point of the $i$-th study $(i=1,2,3 \ldots k)$

$U L_{i}$ : estimated upper limit of $95 \% \mathrm{CI}$ of $B P_{i}$

$S E_{i}$ : SE of estimated break point of the $i$-th study, as calculated by the following equation:

$$
S E_{i} \frac{1}{1.96}\left(U L_{i} B P_{i}\right) .
$$

The individual break points are weighted according to the reciprocal of their variance (calculated as the square of $S E_{i}$ ) giving,

$$
w_{i}=\frac{1}{\left(S E_{i}\right)^{2}}
$$

The integrated break point can be estimated by the fixed model:

$$
\widehat{B P}_{m}=\frac{\sum_{i=1}^{k} w_{i} B P_{i}}{\sum_{i=1}^{k} w_{i}}
$$

The magnitude of variability between studies can be estimated as follows:

$$
\hat{\tau}^{2}=\max \left\{\frac{Q-(k-1)}{\sum_{i=1}^{k} w_{i}-\left(\sum_{i=1}^{k} w_{i}^{2}\right) / \Sigma_{i=1}^{k} w_{i}}, 0\right\}
$$

with

$$
Q=\sum_{i=1}^{k} w_{i}\left(B P_{i}-\widehat{B P}_{m}\right)^{2} \sim \chi_{k-1}^{2}
$$

Weighting including variability between studies is given by,

$$
w_{i}^{*}=\frac{1}{\left(S E_{i}\right)^{2}+\hat{\tau}}
$$

The integrated break point estimated by the DerSimonian and Laird method is given by,

$$
\widehat{B P}_{D L}=\frac{\sum_{i=1}^{k} w_{i}^{*} B P_{i}}{\sum_{i=1}^{k} w_{i}^{*}} .
$$

The estimated $95 \% \mathrm{CI}$ of the integrated break point is given by,

$$
\widehat{B P}_{D L} \pm 1.96 \sqrt{\frac{1}{\sum_{i=1}^{k} w_{i}^{*}}} .
$$

Heterogeneity was assessed using the $I^{2}$ statistic, with Heterogeneity was assessed using the $I^{2}$ statistic, with thresholds of $<25 \%, 50 \%$, and $>75 \%$ considered to represent low, moderate, and high heterogeneity, respectively.

\subsection{Recommended Dietary Allowance Estimation}

The RDA of L-lysine was estimated using the synthesized data on the requirement for L-lysine with reference to the method presented in the Dietary Reference Intakes (DRI) [18]. Given the paucity of data, it was assumed that, for amino acids in DRI report, a similar deviation to protein should be used. Therefore, we calculated this as follows.

Coefficient of variation (CV): $0.12(12 \%)$

$$
R D A=E A R+2 C V=1.24 \times E A R=1.24 \times \widehat{B P}_{D L}
$$

\section{Results}

At first, we estimate break point of L-lysine with statistical integrated analysis using DerSimonian and Laird method. Subsequently, we estimate RDA of L-lysine from synthesized break point. 


\subsection{Statistical Synthesis of Break Point Data}

Table 2. Summary of estimated lysine requirement.

\begin{tabular}{lllllll}
\hline \multirow{2}{*}{ Subject } & \multicolumn{2}{l}{ EAR $(\mathbf{m g} / \mathbf{k g})$ (break point) } & \multicolumn{2}{l}{ RDA $\mathbf{( m g} / \mathbf{k g})$} \\
\cline { 2 - 7 } & mean & Lower 95\%CI & Upper 95\%CI & mean & Lower 95\%CI & Upper 95\%CI \\
\hline Men & 38.9 & 27.6 & 50.2 & 48.2 & 34.2 & 62.2 \\
Women & 36.1 & 29.5 & 42.7 & 44.8 & 36.6 & 52.9 \\
ALL & 36.8 & 31.2 & 42.5 & 45.6 & 38.7 & 52.7 \\
\hline
\end{tabular}

EAR: estimated average requirement, RDA: recommended dietary allowance

The break point in males obtained from three independent studies was estimated as $38.9(\mathrm{mg} / \mathrm{kg})$, with a $95 \%$ CI of 27.6 to $50.2(\mathrm{mg} / \mathrm{kg})$ (Figure 1). No heterogeneity was observed between the tests, and it was confirmed that the break point values obtained from each study were similar $\left(\tau^{2}=0, I^{2}=0\right)$.

One study of IAAO in healthy adult females provided break point values for each of the follicular and luteal phases. The luteal phase showed higher values, but there was no significant difference in the heterogeneity and the 95\% CI of the break point in the two phases. The estimated break point was $36.1 \mathrm{mg} / \mathrm{kg}$ and its $95 \%$ CI was $29.5-42.7$.

In the subgroup analyses, no significant differences were observed. Therefore, there was no sex-based difference in the value of the estimated break point. The result of the break point from the data synthesis in all studies was $36.8 \mathrm{mg} / \mathrm{kg}$, with $95 \%$ CI of $31.2-42.5\left(\tau^{2}=0, I^{2}=0\right)$.

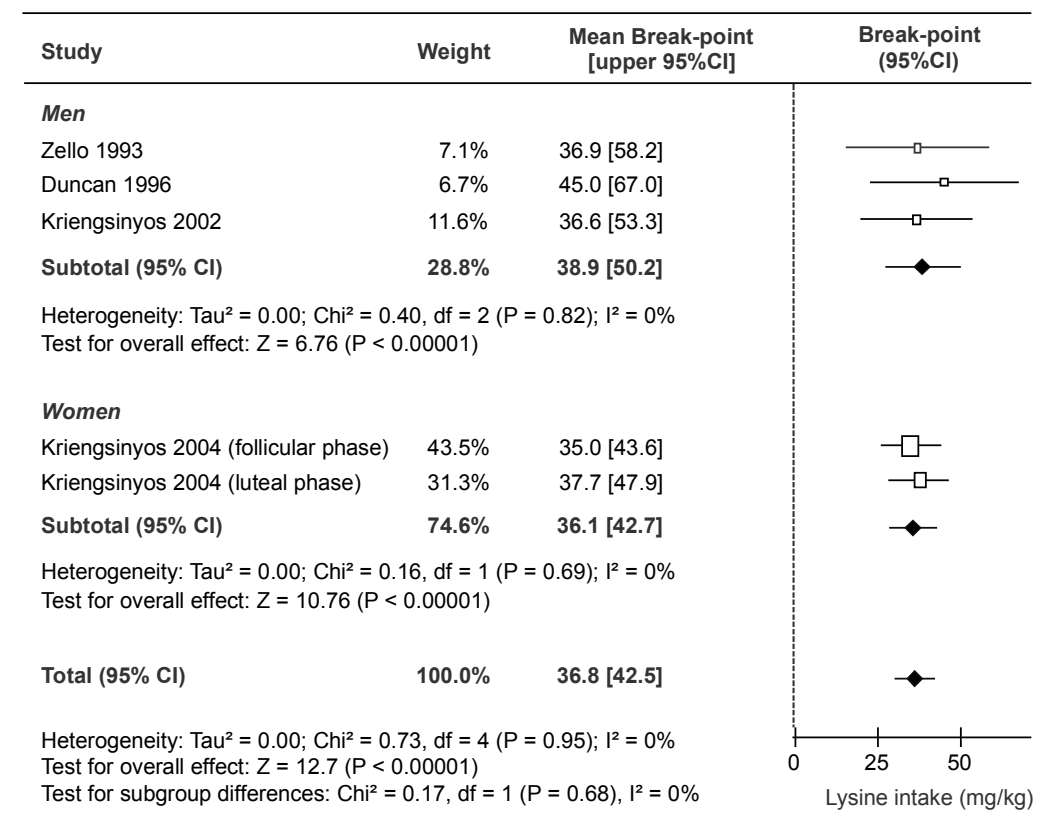

Figure 2. Data synthesis of L-lysine requirement from the IAAO profile of a healthy aduhayamizu

\subsection{Recommended Dietary Allowance Estimation}

The RDA was estimated using the result of data synthesis of break point. Since a break point is equivalent to the EAR, $95 \%$ CI of the break point can be interpreted as $95 \%$ CI of the EAR. The average estimated RDA was $48.2 \mathrm{mg} / \mathrm{kg}$ for males and $44.8 \mathrm{mg} / \mathrm{kg}$ for females. The total was $45.6 \mathrm{mg} / \mathrm{kg}$ and its $95 \%$ CI was $38.7-52.7 \mathrm{mg} / \mathrm{kg}$ (Table 2).

\section{Discussion}

In the present study, a statistical approach was performed to estimate the L-lysine requirements of healthy adults using results from an independent IAAO trial. The reason why we targeted the test results of IAAO in this research is that, in recent years, this method has become a mainstream test for estimating the required amount of essential amino acids. In the DRI report, the L-lysine requirement of adults ( $>19$ years) was calculated first as the EAR and then using the protein requirement $\mathrm{CV}$ to calculate the RDA [18]. In the DRI report, the EAR of lysine was calculated by the arithmetic mean of all reported lysine requirement values, including that based on the $\mathrm{N}$ balance method, which was $31 \mathrm{mg} / \mathrm{kg}$. In addition, the RDA was calculated as $1.24 \times$ EAR. The calculated RDA was rounded to the nearest whole number, which was $38 \mathrm{mg} / \mathrm{kg}$. However, these values need to be re-assessment for two reasons: how to estimate the EAR and how to calculate the RDA.

\subsection{Estimated Average Requirement of Lysine}

The EAR is obtained by calculating the arithmetic mean of point estimations of the requirement for lysine obtained from 
each study [18]. This involves simple pooled data synthesis. Since various intervals of estimation for the requirement were obtained in each study, the data should be synthesized by weighting with the interval estimator. Furthermore, the variation in the requirement for lysine can be reflected by the intra-test error and inter-test error. For these reasons, we applied the DerSimonian and Laired method to synthesize the requirement for lysine. By using this method, there was an effect of narrowing the $95 \%$ CI of the EAR. This was interpreted as a successful narrowing down of the true EAR. For example, the widths of the $95 \%$ CI of the break point of Zello et al. [5], Duncan et al. [6], and Kriengsinyos et al. [7] were 42.7 (= upper 95\% CI - lower 95\% CI $=58.2-15.5$ ), 44.0 , and 33.4, respectively. However, the width of the $95 \%$ CI after data synthesis was reduced to 22.6.

In this study, only the requirement data estimated by the IAAO method were used, but as a tracer method, Kurpad et al. reported the lysine requirements by the $24 \mathrm{~h}$ IAAB method, from which the value was about $30 \mathrm{mg} / \mathrm{kg}[11,12]$. The $24 \mathrm{~h}$ IAAB included adaptation to lysine intake for $6 \mathrm{~d}$ followed by measurement of indicator amino acid oxidation (usually 1-13C-leucine) during a $24 \mathrm{~h}$ period (12 $\mathrm{h}$ fasted and $12 \mathrm{~h}$ fed). This method allows the calculation of $24 \mathrm{~h}$ IAAB, which is derived by subtracting leucine oxidation from leucine intake. The $24 \mathrm{~h}$ IAAB uses intravenous isotope infusion for $24 \mathrm{~h}$ and involves the collection of breath and blood samples to measure plasma enrichment of the isotope. However, the protocol is demanding and invasive [2, 15]. The differences between the IAAO and $24 \mathrm{~h}$ IAAB methods include the period of adaptation and measurements being performed during fed/fasted conditions. In a study on adult humans [19], it was shown that an adaptation period prior to the intake of various levels of lysine did not influence the primary variable $\left(\mathrm{F}^{13} \mathrm{CO} 2\right)$ used to determine the IAAO response, so in the IAAO method it was shown that no prior adaptation to the level of the tested amino acid was needed. With respect to measurements during fed and fasted conditions, there is evidence from the $24 \mathrm{~h}$ IAAB study that the requirements for lysine derived from $12 \mathrm{~h}$ fed and $24 \mathrm{~h}$ oxidation measurements do not differ [11]. Furthermore, not all subjects in the IAAB studies undertook intake of all levels of the tested amino acid because of the invasive nature. By comparison, the IAAO model is minimally invasive, less demanding, and more rapid, thereby allowing multiple test intakes over a wide range from deficiency to excess. Each subject was studied at all test intakes with the number of test intakes being six to seven, thereby allowing the determination of individual amino acid requirements, as well as a statistically stronger estimate of these requirements. For these reasons, as well as the advantages of the IAAO method detailed above, it is possible to apply the IAAO model to determine amino acid requirements in children and in diseased conditions. In this study, because of the differences in the nature of the study and the statistical accuracy of the obtained estimated requirement data between the IAAO method and the $24 \mathrm{~h}$ IAAB, data synthesis analysis of the two was not performed. Studies with the indicator amino acid oxidation method, with L-[1-13C] phenylalanine without prior adaptation to the diet, have generally indicated higher values $(35-45 \mathrm{mg} / \mathrm{kg} / \mathrm{d})$ than other methods including IAAB; however, the reasons for this are not understood [4]. Theoretically, the $24 \mathrm{~h}$ IAAB model is considered to be better suited to determining amino acid requirements, although, from a practical perspective, the IAAO method is better suited. The greatest advantages of the IAAO method are that it is less invasive and minimizes the burden on the subject. Therefore, there does not appear to be a systematic bias due to the choice of method. Owing to the minimal invasiveness of the IAAO method, it is now possible to determine amino acid requirements in other vulnerable populations, including children [10, 19] and pregnant women [9]. If the test results of $24 \mathrm{~h}$ IAAB are also used for data synthesis, the required amount of lysine will be $35 \mathrm{mg} / \mathrm{kg}$ (95\% CI: 26.6-43.4) (data not shown).

\subsection{Estimated Recommended Dietary Allowance of Lysine}

We first performed point and interval estimations of the EAR in order to predict the RDA of lysine. The RDA is defined as the "average daily level of intake sufficient to meet the nutrient requirements of nearly all (97\%-98\%) healthy people" [18]. In other words, since the nutrient requirement varies by individual, information on the inter-individual error in the required amount is necessary in order to estimate the RDA. In this study, we used the CV $(=0.12)$ value that was used in the DRI report to estimate lysine's RDA [18]. The estimated RDA for lysine in healthy males averaged about $48 \mathrm{mg} / \mathrm{kg}$ and that in healthy females averaged about $44.8 \mathrm{mg} / \mathrm{kg}$ (see Table 2). For both sexes combined, the estimated RDA averaged about $46 \mathrm{mg} / \mathrm{kg}$ and the $95 \%$ CI ranged from 38.7 to $52.7 \mathrm{mg} / \mathrm{kg}$; the lysine requirement that we predicted was thus higher than that previously suggested $(30-31 \mathrm{mg} / \mathrm{kg})[4,18]$.

Next, we compared the estimated RDA with the intake of lysine taken from the daily diet.

The intake of L-lysine from food by adults with adequate diets is in the range of $4-5 \mathrm{~g} / \mathrm{d}[18,20,21]$. Assuming a standard weight of $70 \mathrm{~kg}$ for an adult male, the amount of lysine obtained from a normal diet would be $57-71 \mathrm{mg} / \mathrm{kg}$, which is higher than the estimated RDA. This indicates that a normal diet is sufficient to fulfill the lysine requirement.

In this report, we have not verified any findings for children and pregnant women. The reason for this is that the number of reports on these groups is still small. More reports on the requirements for lysine as determined by the IAAO method including on these groups are necessary in the future.

\section{Conclusion}

The present study showed that the estimated values of EAR of lysine for healthy males and females were about 39 and 36 $\mathrm{mg} / \mathrm{kg}$, respectively using random effect model. In addition, the estimated RDA of lysine for healthy people was about 46 $\mathrm{mg} / \mathrm{kg}$. Both of these values are higher than previously suggested. 


\section{References}

[1] C. D. Williams, "A nutritional disease of child-food associated with amaze diet," Arch. Dis. Child., vol. 8, pp. 423-433, 1933.

[2] R. Elango, R. O. Ball, and P. B. Pencharz, "Recent advances in determining protein and amino acid requirements in humans," Br. J. Nutr., vol. 108 Suppl. 2, S22-30, 2012.

[3] D. Tomé and C. Bos, "Lysine requirement through the human life cycle,” J. Nutr., vol. 137 (Suppl. 2), pp. 1642S-1645S, 2007.

[4] WHO, Energy and Protein Requirements, Report of a Joint FAO/WHO/UNU Expert Committee, WHO Technical Report Series 2007, 935, WHO Geneva.

[5] G. A. Zello, P. B. Pencharz, and R. O. Ball, "Dietary lysine requirement of young adult males determined by oxidation of L- $\left[1-{ }^{13} \mathrm{C}\right]$ phenylalanine," Am. J. Physiol., vol. 264, pp. E677$685,1993$.

[6] A. M. Duncan, R. O. Ball, and P. B. Pencharz, "Lysine requirement of adult males is not affected by decreasing dietary protein,” Am. J. Clin. Nutr., vol. 64, pp. 718-725, 1996.

[7] W. Kriengsinyos, L. J. Wykes, R. O. Ball, and P. B. Pencharz, "Oral and intravenous tracer protocols of the indicator amino acid oxidation method provide the same estimate of the lysine requirement in healthy men," J. Nutr., vol. 132, pp. 2251-2257, 2002.

[8] W. Kriengsinyos, L. J. Wykes, L. A. Goonewardene, R. O. Ball, and P. B. Pencharz, "Phase of menstrual cycle affects lysine requirement in healthy women," Am. J. Physiol. Endocrinol. Metab., vol. 287, pp. E489-496, 2004.

[9] M. Payne, T. Stephens, K. Lim, R. O. Ball, P. B. Pencharz, and R. Elango, "Lysine requirements of healthy pregnant women are higher during late stages of gestation compared to early gestation," J. Nutr., vol. 148, pp. 94-99, 2018.

[10] R. R. Pillai, R. Elango, S. Muthayya, R. O. Ball, A. V. Kurpad, and P. B. Pencharz, "Lysine requirement of healthy, school-aged Indian children determined by the indicator amino acid oxidation technique," J. Nutr., vol. 140, pp. 54-59, 2010.
[11] A. V. Kurpad, M. M. Regan, T. Raj, A. El-Khoury, R. Kuriyan, M. Vaz, D. Chandakudlu, V. G. Venkataswamy, S. Borgonha, and V. R. Young, "Lysine requirements of healthy adult Indian subjects receiving long-term feeding, measured with a 24-h indicator amino acid oxidation and balance technique," Am. J. Clin. Nutr., vol. 76, pp. 404-412, 2002.

[12] A. V. Kurpad, T. Raj, A. El-Khoury, L. Beaumier, R. Kuriyan, A. Srivatsa, S. Borgonha, A. Selvaraj, M. M. Regan, and V. R. Young, "Lysine requirements of healthy adult Indian subjects, measured by an indicator amino acid balance technique," Am. J. Clin. Nutr., vol. 73, pp. 900-907, 2001.

[13] K. I. Kim, I. McMillan, and H. S. Bayley, "Determination of amino acid requirements of young pigs using an indicator amino acid,” Br. J. Nutr., 50, 369-382, 1983.

[14] R. O. Ball and H. S. Bayley, "Tryptophan requirement of the $2.5 \mathrm{-kg}$ piglet determined by the oxidation of an indicator amino acid," J. Nutr., vol. 114, pp. 1741-1746, 1984.

[15] P. B. Pencharz and R. O. Ball, "Different approaches to define individual amino acid requirements," Annu. Rev. Nutr., vol. 23, pp. 101-116, 2003.

[16] G. Seber and A. Lee, Linear Regression Analysis, 2nd ed., New York: Wiley-interscience, 2003.

[17] R. DerSimonian and N. Laird, "Meta-analysis in clinical trials," Control Clin. Trials, vol. 7, pp. 177-188, 1986.

[18] IOM, Dietary Reference Intakes for Energy, Carbohydrate, Fiber, Fat, Fatty Acids, Cholesterol, Protein and Amino Acids, Washington DC: The National Academies Press, 2005.

[19] R. R. Pillai, R. Elango, R. O. Ball, A. V. Kurpad, and P. B. Pencharz, "Lysine requirements of moderately undernourished school-aged Indian children are reduced by treatment for intestinal parasites as measured by the indicator amino acid oxidation technique,” J. Nutr., vol. 145, pp. 954-959, 2015.

[20] M. Iwasaki, J. Ishihara, R. Takachi, H. Todoriki, H. Yamamoto, H. Miyano, T. Yamaji, and S. Tsugane, "Validity of a self-administered food-frequency questionnaire for assessing amino acid intake in Japan," J. Epidemiol., vol. 26, pp. 36-44, 2016.

[21] P. L. Pellett and S. Ghosh, "Lysine fortification: past, present, and future," Food Nutr. Bull., vol. 25, pp. 107-113, 2004. 